\title{
Breast cancer diagnosis and treatment: Asian perspective
}

\author{
Anurag Gupta ${ }^{1}$, Rohit Joshi \\ ${ }^{1}$ Department of Breast \& Endocrine Surgery, Lyell McEwin and Modbury Hospitals, ${ }^{2}$ Department of Medical Oncology, Lyell McEwin Hospital, \\ University of Adelaide, Adelaide, SA, Australia \\ Correspondence to: Mr. Anurag Gupta, MS, FRACS. Consultant Surgeon, Department of Breast \& Endocrine Surgery, Lyell McEwin Hospital, \\ Haydown Road, Elizabeth Vale, SA 5112, Australia. Email: anurag.gupta@sa.gov.au. \\ Comment on: Jiang Z, Song E, Wang X, et al. Guidelines of Chinese Society of Clinical Oncology (CSCO) on Diagnosis and Treatment of Breast \\ Cancer (2020 version). Transl Breast Cancer Res 2020. doi: 10.21037/tbcr-2020-2.
}

Received: 22 October 2020; Accepted: 28 October 2020; Published: 31 October 2020.

doi: $10.21037 /$ tbcr-20-55

View this article at: http://dx.doi.org/10.21037/tbcr-20-55

Breast cancer is the commonest cancer and the fifth leading cause of cancer deaths among women worldwide. Approximately 1.67 million women were diagnosed with breast cancer and over half a million women died from it in 2012. This corresponds to over quarter of all cancers and about $14.7 \%$ of all cancer deaths in women (1). Breast cancer incidence and mortality rates vary significantly across the globe (1). The incidence is much higher in Western Europe and North America compared to Asian region. In East Asian women breast cancer incidence is about 27.0 per 100,000 women, compared to over 91.1 per 100,000 women in Western Europe or Northern America (1).

Unfortunately, the incidence of breast cancer is increasing across most regions of the world (2). This increasing incidence is attributed to several factors like, use of screening mammography, social and life-style changes, obesity, economic development and change in reproductive behaviour (3). The incidence of breast cancer has doubled or tripled in Japan, Korea, Hong Kong and Singapore over past 40 years (4-6).

China is the largest and the most populous country in the world with an estimated population of nearly 1.42 billion (7). Breast cancer is the commonest cancer for women in China with 367,900 new cases diagnosed in 2018, accounting for about one fifth of all cancer cases in women in 2018 (7). With changes in reproductive practices, such as lower parity and reduced breastfeeding, social and lifestyle changes, rapid economic development along with nationwide family planning program started in 1970s are all likely to play a crucial part in significantly increasing breast cancer incidence in China.
Despite increasing breast cancer incidence, breast cancer mortality has been declining in western countries since 1980s. Early detection, use of breast cancer screening program and improved adjuvant treatment are greatly contributing to this declining breast cancer mortality rates (8). Similar declining breast cancer mortality trends are observed in Asian region, which are also most likely attributable to same factors (7).

Although several national breast cancer screening programs have been initiated by the Chinese government since the late 2000s but the coverage of these screening programs for the general population is limited. According to a report in 2010, the coverage of breast cancer screening was only $27.4 \%$ in Shanghai and $21.7 \%$ for all of China (9). Due to a low cost and huge population, clinical breast examination (CBE) is the primary breast cancer screening modality currently used in China (10). It has unclear efficacy unlike screening mammography in detecting asymptomatic early breast cancers.

Currently available evidence-based guidelines for breast cancer diagnosis and treatment are primarily based on studies from the western world. Unfortunately, there is significant lack of high quality randomised controlled studies from developing countries. With growing evidence of biological behaviour and genetics of breast cancer and its clinical implications, it is increasingly important to have clinical guidelines based on evidence from local studies.

As breast cancer incidence in China is likely to increase significantly in the future due to a variety of reasons, there is a need for local evidence-based guidelines for early diagnosis and treatment. China's large size and population, 
make it harder for diagnostic and treatment resources to be universally available and affordable.

Systemic therapies for breast cancer have evolved over time with a variety of choices available now. Multiple randomised controlled studies and meta-analysis have supported the use for systemic therapy in the adjuvant as well as the advanced care settings. Treatment can be in the form of cytotoxic medications, targeted drugs or hormone modulation. The authors of the Chinese Society of Clinical Oncology (CSCO) guidelines (11) have done a commendable job in listing the systemic options available and highlighting the differences. These guidelines would serve the junior oncology registrars as well as the senior consultants.

One of the transformational changes in cytotoxic therapy regimens has been supportive care with regard to anti-nausea medications, bone marrow support and good treatment of serious adverse effects.

Metastasis to the bones is managed with bisphosphonates and RANKL modulators, along with radiotherapy. Also, metastasis to the brain is managed more aggressively with radiotherapy (including stereo-tactic radiosurgery), surgery and chemotherapy.

Biopsies will be transformed and from age old core biopsies to liquid biopsies and circulating tumour cells. These will change the way patients are diagnosed and monitored for signs of cancer recurrence.

Automation for various processes is moving ahead with better computing and artificial intelligence.

In this current issue, Jiang et al. (11) have compiled evidence-based CSCO guidelines for Breast Cancer Diagnosis and Treatment is an important step in this direction. These guidelines examine available evidence, rationalise resources and provide clinical guidelines for regional clinicians. Although, some recommendations are based on western studies, but increasing numbers of robust Asian studies would help in future CSCO guidelines.

These guidelines also provide a brief overview on technological advances and their role in breast cancer diagnosis and management. Currently, there are large number of studies in progress looking into breast cancer genetics, immunotherapy and role of artificial intelligence in improving outcomes in breast cancer management. Once established, this would help in taking steps beyond the traditional diagnostic approaches, which have been shown to be reliable, efficient and cost-effective. In this issue, Jiang and colleagues (11) have covered the most recent trends regarding the aspects of diagnostic modalities, management, and prognosis in the field of breast cancer.

\section{Acknowledgments}

Funding: None.

\section{Footnote}

Provenance and Peer Review: This article was commissioned by the Editorial Office, Translational Breast Cancer Research. The article did not undergo external peer review.

Conflicts of Interest: Both authors have completed the ICMJE uniform disclosure form (available at http://dx.doi. org/10.21037/tbcr-20-55). The authors have no conflicts of interest to declare.

Ethical Statement: The authors are accountable for all aspects of the work in ensuring that questions related to the accuracy or integrity of any part of the work are appropriately investigated and resolved.

Open Access Statement: This is an Open Access article distributed in accordance with the Creative Commons Attribution-NonCommercial-NoDerivs 4.0 International License (CC BY-NC-ND 4.0), which permits the noncommercial replication and distribution of the article with the strict proviso that no changes or edits are made and the original work is properly cited (including links to both the formal publication through the relevant DOI and the license). See: https://creativecommons.org/licenses/by-nc-nd/4.0/.

\section{References}

1. Ferlay J, Soerjomataram I, Dikshit R, et al. Cancer incidence and mortality worldwide: sources, methods and major patterns in GLOBOCAN 2012. Int J Cancer 2015;136:E359-86.

2. World Cancer Report 2014. Lyon: International Agency for Research on Cancer, 2014.

3. Vineis P, Wild CP. Global cancer patterns: causes and prevention. Lancet 2014;383:549-57.

4. Porter P. "Westernizing" women's risks? Breast cancer in lower-income countries. N Engl J Med 2008;358:213-6.

5. Wong IO, Schooling CM, Cowling BJ, et al. Breast cancer incidence and mortality in a transitioning Chinese population: current and future trends. Br J Cancer 2015;112:167-70. 
6. Virani S, Sriplung H, Rozek LS, Meza R. Escalating burden of breast cancer in southern Thailand: analysis of 1990-2010 incidence and prediction of future trends. Cancer Epidemiol 2014;38:235-43.

7. Global Cancer Observatory: Cancer Today. Lyon, France: International Agency for Research on Cancer, 2018.

8. Hermon C, Beral V. Breast cancer mortality rates are levelling off or beginning to decline in many western countries: analysis of time trends, age-cohort and ageperiod models of breast cancer mortality in 20 countries. Br J Cancer 1996;73:955-60.

doi: $10.21037 /$ tbcr-20-55

Cite this article as: Gupta A, Joshi R. Breast cancer diagnosis and treatment: Asian perspective. Transl Breast Cancer Res 2020;1:22.
9. Wang B, He M, Wang L, et al. Breast cancer screening among adult women in China, 2010. Prev Chronic Dis 2013;10:E183.

10. Zheng Y. Approaches to Breast Cancer Early Detection and Screening in China. Chicago: The Breast Health Global Initiative, 2010.

11. Jiang Z, Song E, Wang X, et al. Guidelines of Chinese Society of Clinical Oncology (CSCO) on Diagnosis and Treatment of Breast Cancer (2020 version). Transl Breast Cancer Res 2020. doi: 10.21037/tbcr-2020-2. 